\section{BMJ Open Respiratory Research}

\title{
Early NIV is associated with accelerated lung function decline in Duchenne muscular dystrophy treated with glucocorticosteroids
}

\author{
Megan E Angliss, ${ }^{1}$ Kiara D Sclip, ${ }^{1}$ Leanne Gauld (D) ${ }^{1,2}$
}

To cite: Angliss ME, Sclip KD, Gauld L. Early NIV is associated with accelerated lung function decline in Duchenne muscular dystrophy treated with glucocorticosteroids. BMJ Open Resp Res 2020;7:e000517. doi:10.1136/ bmjresp-2019-000517

- Additional material is published online only. To view please visit the journal online (http://dx.doi.org/10.1136/ bmjresp-2019-000517)

Received 20 0ctober 2019 Revised 21 January 2020 Accepted 31 January 2020
Check for updates

(C) Author(s) (or their employer(s)) 2020. Re-use permitted under CC BY-NC. No commercial re-use. See rights and permissions. Published by BMJ

${ }^{1}$ Respiratory Medicine, Children's Health Queensland Hospital and Health Service, South Birsbane, Queensland, Australia

${ }^{2}$ School of Medicine, University of Queensland, St. Lucia, Queensland, Australia

Correspondence to

Dr Leanne Gauld;

Leanne.gauld@health.qld. gov.au

\section{ABSTRACT}

Background Use of non-invasive ventilation (NIV) in adolescents with Duchenne muscular dystrophy (DMD) has increased with concomitant extended survival.

Aim To describe lung function (LF) changes with NIV in adolescents with DMD and to assess differences between Steroid Users and Steroid Naïve subjects.

Method A retrospective cohort of adolescents with DMD initiating NIV over 10 years was conducted. Serial LF before and after NIV initiation was collated. Use of systemic glucocorticosteroids, adherence to NIV and presence of cardiac disease were assessed.

Results Twenty-nine men started NIV, median age 14.66 years (IQR 2.35, 10.47-17.96). Nine were Steroid Users and eight were Steroid Naïve. Indications for NIV were apnoea-hypopnoea index $>5$ and/or nocturnal hypoventilation. LF is better (forced vital capacity (FVC) $z$-score -3.26 vs $-5.41, p<0.02$ ) and decline slower (FVC z-score -0.58 per annum (pa) vs $-0.68 \mathrm{pa}, \mathrm{p}<0.001$ ) in Steroid Users compared with Steroid Naïve subjects. Following NIV initiation, FVC z-score decline slowed for the whole $(-0.72 \mathrm{pa}(95 \% \mathrm{Cl}-0.79$ to 0.64$)$ to $-0.46 \mathrm{pa}$ $(95 \% \mathrm{Cl}-0.54$ to 0.38$) \mathrm{p}<0.001)$ and Steroid Naïve groups $(-0.74(95 \% \mathrm{Cl}-0.85$ to 0.63$)$ to $-0.44 \mathrm{pa}(95 \% \mathrm{Cl}$ -0.56 to 0.32$) p<0.001)$ but accelerated in the Steroid User group ( $-0.56(95 \% \mathrm{Cl}-0.70$ to 0.42$)$ to $-0.75 \mathrm{pa}$ $(95 \% \mathrm{Cl}-0.89$ to 0.61$) \mathrm{p}<0.001)$. Adherence to NIV and cardiac disease did not impact decline.

Conclusion Overall, LF decline is reduced on NIV. Steroid Naive patients have lower LF and faster decline, which slows following NIV initiation. An accelerated LF decline was seen on NIV in Steroid Users which requires further prospective research.

\section{INTRODUCTION}

The use of non-invasive ventilation (NIV) support in children has increased rapidly over the past decade. The life expectancy of children with Duchenne muscular dystrophy (DMD) has been improving in conjunction with the expanded use of glucocorticosteroids, NIV, improved airway clearance techniques and cardiac medications. ${ }^{12}$ The contribution to increased life expectancy by each of these therapies is largely unknown,

\section{Key messages}

Is the early use of non-invasive ventilation (NIV) in Duchenne muscular dystrophy (DMD) detrimental to lung function (LF) decline in Duchenne's patients who are treated with long-term glucocorticosteroids?

- The published guidelines to care for DMD suggest earlier use on NIV, starting for sleep disordered breathing, even before hypoventilation is present. In long-term Steroids Users, LF decline is accelerated after starting NIV using these criteria, potentially worsening their outcome.

- This study compares and describes LF decline in adolescents with DMD who have started NIV for sleep disordered breathing with or without hypoventilation. It confirms previous reports of slowing decline in the Steroid Naiive group but accelerated LF decline after starting NIV in Steroid Users. This has not been previously reported.

and it is likely to be complex. Without NIV, the mean survival after detection of nocturnal hypercarbia is 9.7 months. ${ }^{3}$ When NIV is used in chest wall and non-progressive neuromuscular disorders, survival at 1 year is $90 \%$ and at 2 years is $80 \%{ }^{4}$ Survival on NIV has not been characterised as well in progressive neuromuscular weakness disorders such as DMD.

NIV is known to improve quality of life by reduction in symptoms but worse outcomes have been reported when started prophylactically (before hypoventilation is present). ${ }^{56}$ Brasil Santos et al, 2016 described a group of 71 adults with DMD who were all on angiotensin-converting enzyme inhibitor (ACEI) and were Steroid Nä̈ve. When started on NIV, the rate of decline of forced vital capacity (FVC) \% predicted reduced from $4.28 \%$ to $1.36 \%$ per annum (pa). However, many of the subjects did not have lung function (LF) results available for the period prior to NIV initiation and no subjects were Steroid Users, leaving the impact of glucocorticosteroids unknown. The long-term use of 
glucocorticosteroids has previously been shown to lead to a higher peak and a delayed decline in FVC \% predicted, but the impact of NIV has not been investigated in these studies. ${ }^{89}$ A better understanding of the impact of NIV to LF decline in DMD will lead to better informed management strategies in DMD. The aim of this study was to describe and analyse LF changes with initiation of NIV in children with DMD and to assess for differences between Steroid Users and Steroid Naïve subjects.

\section{METHODS}

\section{Data collection}

A retrospective clinical audit of children with DMD who were initiated on NIV in the past 10 years was conducted. Children were identified by searching two comprehensive databases held by Children's Health Queensland, containing clinical information. The first is held by the sleep unit and contains information about all polysomnographies (PSGs) performed in Queensland. The second is held by the neuromuscular service and contains clinical information about all children in Queensland with an identified neuromuscular disease. Both databases were searched using the search criteria:

1. Diagnosis: DMD.

2. PSG date: June 2008-June 2018.

3. PSG type: NIV.

A comprehensive chart review was undertaken to ensure patients met inclusion criteria and to gather clinical data. The data collected were:

1. Date of birth.

2. Date and diagnostic PSG findings.

3. Date and NIV titration findings.

4. Final NIV settings.

5. All adherence to NIV data available.

6. All serial LF tests and anthropometric values.

7. Date of death or transfer to adult care.

8. Start and finish dates of systemic glucocorticosteroids, where applicable.

9. All echocardiogram results were reviewed for presence of dilated cardiomyopathy and ejection fraction.

10. Spinal surgery.

\section{Steroid use classification}

Patients were considered long-term Steroid User if using glucocorticosteroids (prednisolone of deflazacort) for $>5$ years, Steroid Nä̈ve if have never used and Intermittent Users if 1-5 years of use. Use of glucocorticosteroids was generally doctor or patient preference driven, and cessation was generally due to development of side-effects.

\section{Polysomnography}

Full diagnostic PSG were performed annually when the FVC was below $50 \%$ predicted or when sleep symptoms existed. PSG was performed in the sleep laboratory of CHQ using EMBLA (N7000, Natus Neuro, Middleton, Wisconsin, USA) equipment. The following channels were used: electroencephalogram, electro-oculogram, chin and diaphragm electromyogram, thoracic and abdominal effort respiratory impedance plethysmography bands, nasal airflow, thermistor, body position, ECG, oxygen saturation $\left(\mathrm{SpO}_{2}\right)$, transcutaneous carbon dioxide $\left(\mathrm{TcCO}_{2}\right)$ and a full audio and video recording. Studies were attended by trained paediatric sleep nurses and were manually scored by a qualified paediatric sleep physician using the American Academy of Sleep Medicine 2012 paediatric criteria. ${ }^{10}$ The specific PSG data extracted for analysis were: apnoea-hypopnoea index (AHI) (total and in rapid eye movement (REM)/nonrapid eye movement (NREM) sleep, central AHI (total and in REM/NREM sleep), obstructive AHI (total and in REM/NREM), $\mathrm{TcCO}_{2}$ (mean, maximum and per cent of total sleep time (TST) $>50 \mathrm{~mm} \mathrm{Hg}$ ), $\mathrm{SpO}_{2}$ (mean and nadir).

Sleep disordered breathing was treated if:

1. Total AHI $>5 /$ hour.

2. Hypoventilation-maximum $\mathrm{TcCO}_{2}>55 \mathrm{~mm} \mathrm{Hg}$ or $\mathrm{TcCO}_{2}>50 \mathrm{~mm} \mathrm{Hg}$ for $2 \%$ of TST.

If the obstructive AHI $>5 /$ hour, then treatment with adenotonsillectomy was considered. Those with ongoing sleep disordered breathing after adeontonsillectomy or without adenotonsillar hypertrophy and those with only central sleep disordered breathing were treated with NIV. Children requiring NIV underwent NIV titration studies using a standard manual titration protocol to adjust the interface and ventilator settings and optimise breathing parameters, synchrony and gas exchange. Patients have undergone annual NIV titration studies once established on NIV, where minor changes to NIV settings may be made to ensure synchrony and normal gas exchange.

The criteria used for diagnosing hypoventilation changed from a maximum $\mathrm{TcCO}_{2}>55 \mathrm{~mm} \mathrm{Hg}$ prior to March 2018 to $2 \%$ of TST $>50 \mathrm{~mm} \mathrm{Hg}$ following this time. ${ }^{11}$ The $\%$ TST $>50 \mathrm{~mm} \mathrm{Hg}$ was not included in the reports prior to this date. PSG before November 2014 were not accessible to re-evaluate due to a hospital relocation. The last 12 diagnostic PSG were reanalysed for maximum $\mathrm{TcCO}_{2}$ and \% time $\mathrm{TcCO}_{2}>50 \mathrm{~mm} \mathrm{Hg}$.

\section{Lung Function testing}

Spirometry was performed using standard methods according to American Thoracic Society/European Respiratory Society guidelines. The CareFusion's Vyntus PNEUMO system (Hoechberg, Germany) was used with SentrySuite software in the seated position with a nose clip and bacterial filter (SureGard; BirdHealthcare, Australia). Height was predicted using ulna length. ${ }^{12}$ Racial background was considered when choosing prediction equations, and 'other' was used where racial background could not be clearly defined. To account for the early normal LF expected in DMD, before steadily declining throughout the second decade, only the LF performed $>10$ years age was included in the rates of decline data. 
Cardiac disease classification

Cardiac disease was considered significant if the ejection fraction was $<50 \%$ or dilated cardiomyopathy was seen on echocardiogram.

\section{Statistical analysis}

Descriptive statistics were used where appropriate. Regression analysis was used to find relationships between duration of steroid use and age of NIV initiation. For rates of decline, the fitted random-effects models with a matrix-weighted average of the between and within results (allowing for differing numbers of tests for individuals) were used and reported as mean (IQR). Differences in rates of decline in LF were assessed by correlations between random effects models and $p$ values were reported. The influence of long-term steroid use and non-adherence to NIV was assessed using the same methods. Differences in LF prior to beginning NIV and differences in PSG findings before and after commencing NIV were assessed with the Mann-Whitney U test. A p value $<0.05$ was considered significant. Intermittent Users were excluded from steroid use subgroup analysis of rates of decline pre-NIV and post-NIV a priori, as the durations of steroid use varied, and the applicability of these results would be difficult to determine.

\section{Patient and public involvement}

No patients or public were involved in the design, conduct, reporting or dissemination of our research.

\section{RESULTS}

\section{Descriptive Statistics}

Twenty-nine men with DMD started NIV during the 10-year study period. Two patients died and three have since transferred to adult facilities without ongoing information collection beyond their 19th birthdays. One patient who died was Steroid Nä̈ve and died at age 18.8 years from cardiac failure. The second used prednisolone from age 7 to 10 years and died at age 17.0 years due to a lower respiratory tract infection.

Nine patients $(31.0 \%)$ were Steroid Users, 8 (27.6\%) were Steroid Nä̈ve and 12 (41.4\%) were Intermittent Users. In subjects who started glucocorticosteroids, the median age of starting was 6 years (IQR 2.5, range 4-8). Subjects starting glucocorticosteroids began on $0.25 \mathrm{mg} / \mathrm{kg}$ of prednisolone and changed to deflazacort if side effects were significant (see table 1 ).

\section{Polysomnography findings}

The only significant difference in diagnostic PSG findings was that maximum $\mathrm{TcCO}_{2}$ levels were higher in Steroid Nä̈ve compared with Steroid Users (see table 2). No significant differences were seen between the Steroid User and Steroid Naïve groups for age of NIV initiation. No relationship was found between duration of steroid use and age of NIV initiation $(\mathrm{r}=0.15, \mathrm{p}=0.44)$.

\begin{tabular}{|c|c|c|c|}
\hline & $\begin{array}{l}\text { Steroid } \\
\text { Naïve }\end{array}$ & $\begin{array}{l}\text { Intermittent } \\
\text { Steroid User }\end{array}$ & $\begin{array}{l}\text { Steroid } \\
\text { User }\end{array}$ \\
\hline & $n=8$ & $n=12$ & $n=9$ \\
\hline \multicolumn{4}{|l|}{$\begin{array}{l}\text { Glucocorticosteroid } \\
\text { treatment used }\end{array}$} \\
\hline Prednisolone & - & 11 & 5 \\
\hline $\begin{array}{l}\text { Prednisolone changed to } \\
\text { deflazacort }\end{array}$ & - & 1 & 4 \\
\hline \multicolumn{4}{|l|}{$\begin{array}{l}\text { Adherence to NIV (median } \\
\text { use) }\end{array}$} \\
\hline$>6$ hours per night & 4 & 9 & 7 \\
\hline 4-6hours per night & 1 & 1 & 1 \\
\hline$<4$ hours per night & 0 & 2 & 0 \\
\hline No download & 3 & 0 & 1 \\
\hline \multicolumn{4}{|l|}{ Cardiac disease present } \\
\hline Ejection fraction $<50 \%$ & 2 & 1 & 0 \\
\hline Dilated cardiomyopathy & 1 & 1 & 0 \\
\hline Both & 0 & 2 & 0 \\
\hline \multicolumn{4}{|l|}{ ACEl status } \\
\hline Prescribed & 5 & 9 & 7 \\
\hline Not prescribed & 2 & 2 & 2 \\
\hline Status unknown & 1 & 1 & 0 \\
\hline Spinal surgery performed & 1 & 6 & 0 \\
\hline
\end{tabular}

ACEI, Angiotensin-converting enzyme inhibitor; NIV, noninvasive ventilation.

Twelve patients underwent re-evaluation for hypoventilation using the criteria of (1) peak $\mathrm{TcCO}_{2}>55 \mathrm{~mm} \mathrm{Hg}$ and (2) $2 \%$ TST $>50 \mathrm{~mm} \mathrm{Hg}$. Six patients were diagnosed as hypoventilation using both criteria, and the remaining six patients were diagnosed as not having hypoventilation by both criteria, with no patients demonstrating a false positive or false negative result.

\section{Non-invasive ventilation}

A statistically significant improvement was found between the last diagnostic sleep study and the NIV titration study for many PSG parameters, particularly respiratory events and gas-exchange abnormalities in REM (see online supplementary table $1 \mathrm{~S}$ and figure 1 ).

All subjects used a nasal interface, and only one individual preferred nasal pillows. The Wisp (Respironics, Murrysville, Pennsylvania, USA) mask was used in the majority $(n=19,65.5 \%)$. All subjects were treated in the spontaneous/timed mode; the inspiratory positive airway pressure required had median $13 \mathrm{~cm} \mathrm{H}_{2} \mathrm{O}$ (IQR 3, range 10-13), expiratory positive airway pressure had median 5 $\mathrm{cm} \mathrm{H}_{2} \mathrm{O}$ (IQR 1, range 4-6).

\section{Effect of adherence to Non-invasive ventilation}

Adherence data from downloading NIV machines were available for 25 subjects $(86.2 \%$ ) (see table 1$)$. If median 


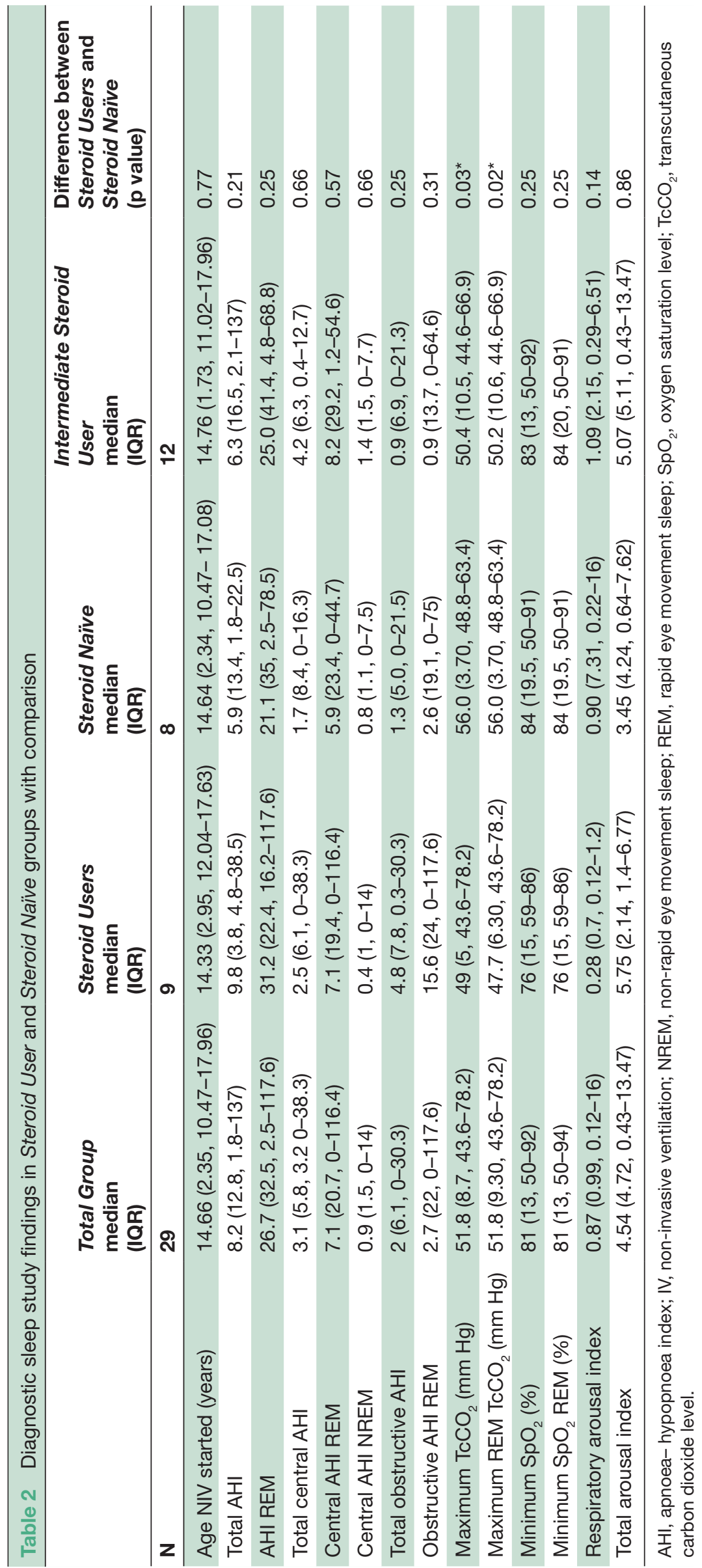



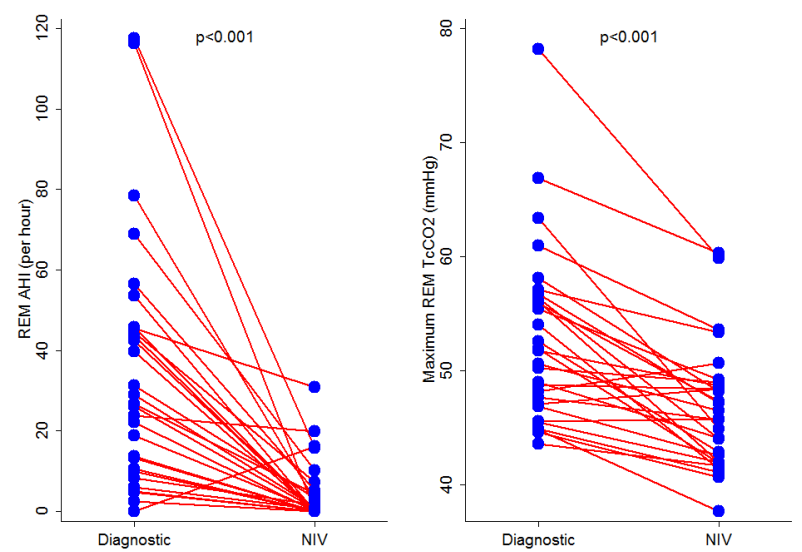

Figure 1 Changes in $\mathrm{AHI}$ and maximum $\mathrm{TcCO}_{2}$ in $\mathrm{REM}$ sleep from the diagnostic to the NIV titration study. AHI, apnoea-hypopnoea index; NIV, non-invasive ventilation; $\mathrm{REM}$, rapideye movement sleep; $\mathrm{TCCO}_{2}$, transcutaneous carbon dioxide level.

adherence for $>4$ hours per night is considered reasonable, then only two Intermittent Users (8\%) did not achieve this. Subjects with median adherence $<4$ hours per night or those in whom no adherence data were collected are excluded from the post-NIV rate of decline analysis, then the rate of decline in FVC $z$-score is not significantly different to that seen for the whole group ( $p>0.05)$.

\section{Lung Function results}

Twenty-four subjects had performed 161 LF (median 6.5 tests, IQR 5, range 2-18) prior to beginning NIV. For age $>10$ years, 23 subjects performed 134 LF tests (median 5, IQR 3, range 2-11) prior to starting NIV. Twenty-two subjects performed 120 tests (median 5, IQR 3 , range 2-10) following NIV initiation.

The annual mean rate of decline in FVC $\mathrm{z}$-score prior to NIV initiation was -0.72 z-score pa (95\% CI -0.79 to 0.64 , SE $0.04, \mathrm{p}<0.01)$ and it significantly slowed following NIV initiation to -0.46 z-score pa $(95 \%$ CI -0.54 to 0.38 , SE 0.04) $\mathrm{p}<0.01$ (see table 3 and figure 2).

\section{Effect of glucocorticosteroids on lung function}

Throughout adolescence, and independent of NIV, LF is greater, and the rate of decline is slower in Steroid Users, compared with those who are Steroid Naïve (see online supplementary tables $3 \mathrm{~S}$ and $4 \mathrm{~S}$ ).

The rate of decline in LF is significantly reduced following NIV initiation in the Steroid Naïve group but accelerated in the Steroid User group and this reaches significance for $\mathrm{z}$-scores and \% predicted values (see table 3 and figure 3 ).

\section{Cardiac disease}

Seven $(24.1 \%)$ subjects met the criteria of significant cardiac disease (see table 1). Twenty-one (72.4\%)

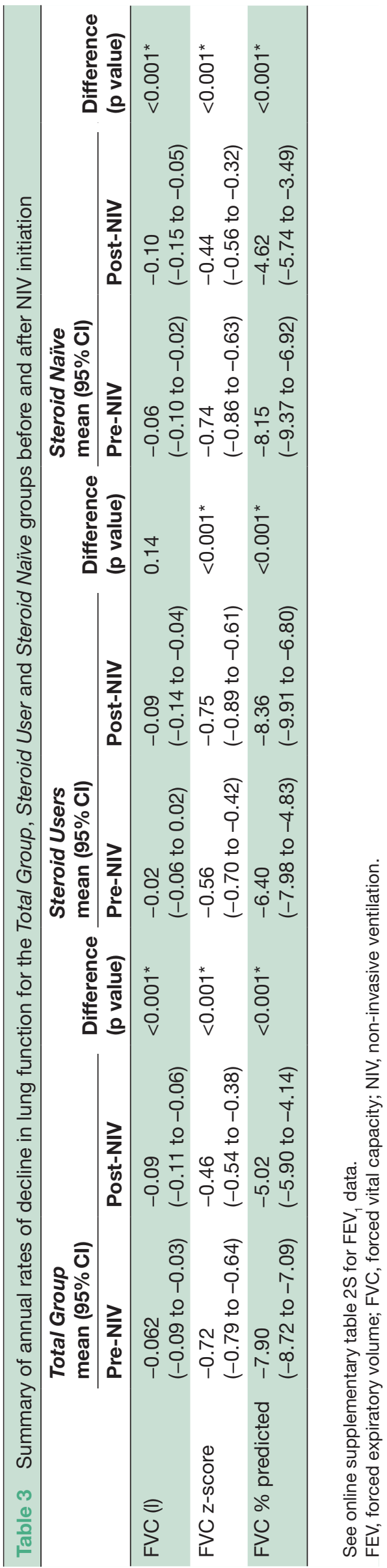




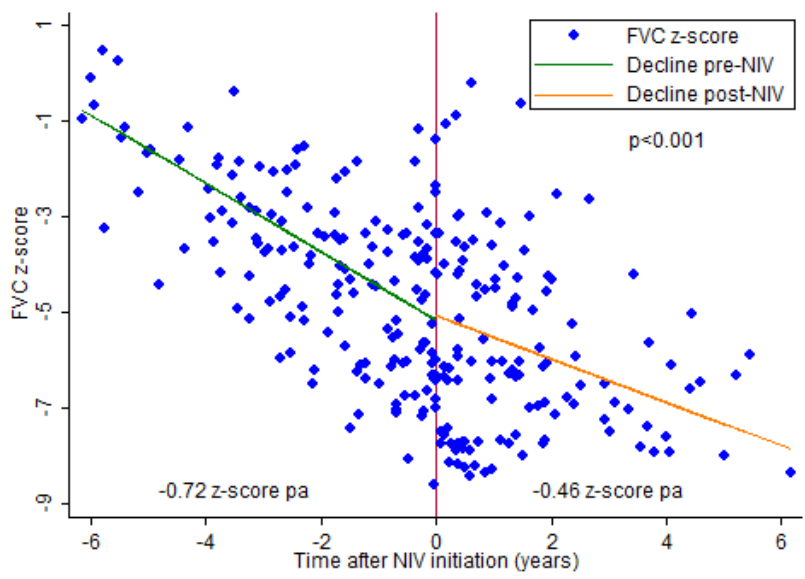

Figure 2 Total Group rate of decline in FVC z-score before (-0.72 pa) and after (-0.46 pa) NIV initiation. FVC, forced vital capacity; NIV, non-invasive ventilation; pa, per annum.

subjects were prescribed an ACEI and six (20.7\%) were not.

In subjects with significant cardiac disease, the FVC z-score reduced at a rate of -0.68 pa $(95 \%$ CI -0.72 to 0.61) per year and for the group without significant cardiac disease, the rate of decline was -0.65 z-scores pa (95\% CI -0.70 to 0.60$)$ with no significant difference between the two groups $(\mathrm{p}=0.38)$. Similarly, although LF was slightly lower in the group with significant cardiac disease, no statistically significant differences were seen in LF parameters or rates of decline before and after NIV initiation for the cardiac disease group compared with those without significant cardiac disease.

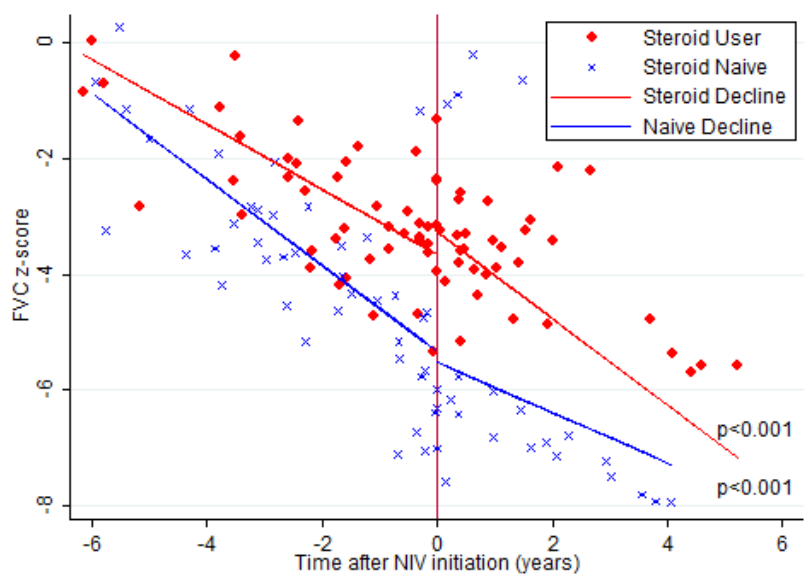

Figure 3 Rates of decline in FVC z-scores before and after NIV initiation for the Steroid User and Steroid Naïve groups. FVC forced vital capacity; NIV, non-invasive ventilation.

\section{DISCUSSION}

This study has confirmed the findings of Brasil Santos $\mathrm{et} \mathrm{al},{ }^{7}$ who have shown that in Steroid Naïve subjects with DMD, the rate of decline in FVC \% predicted is slowed after NIV initiation. However, Steroid Users have demonstrated an unexpected acceleration in LF decline following NIV initiation that has not previously been reported. This finding is not in keeping with the extended survival seen in DMD in the modern era but necessitates further investigation into the benefits and timing of NIV initiation in long-term Steroid Users. The study has confirmed previous reports that LF is higher and the rates of decline in LF are slower in Steroid Users compared with Steroid Naïve subjects. ${ }^{89}$ Steroid User LF remains better than Steroid Naïve LF across the adolescent age range. However, for Steroid Users the rate of LF decline increases to a rate comparable with the Steroid Naïve pre-NIV rates of decline following NIV initiation.

There has been speculation about the best time to start NIV in DMD since the randomised controlled trial of prophylactic NIV in DMD published in 1994. ${ }^{6}{ }^{13-15}$ Initially recommendations were for initiation of NIV only when daytime hypoventilation was present, ${ }^{16}$ but presence of symptoms with sleep only hypoventilation and the risk of sudden and severe deterioration along with the notable benefits of improved quality of life, daytime hypercarbia, reduction in LF rate of decline, reduction in intensive care admissions and improved longevity have led to the gradual introduction of NIV earlier in the progression of sleep disordered breathing. ${ }^{2} 7111718$ The most recently released guide to diagnosis and management of DMD (part 2) has suggested initiation of NIV when (1) $\mathrm{TcCO}_{2}>50 \mathrm{~mm} \mathrm{Hg}$ for $2 \%$ of TST or increases by $10 \mathrm{~mm} \mathrm{Hg}$ from awake baseline, (2) $\mathrm{SpO}_{2}<88 \%$ for $2 \%$ TST or 5 min continually or (3) AHI $>5 /$ hour. $^{11}$ Well-planned, prospective studies have been difficult to do in a large group of patients with DMD, and studies have included other patient cohorts and small numbers of patients with DMD leaving ongoing speculation about the optimal timing for NIV. ${ }^{18}$

Our patient group has used the dual criteria of AHI $>5$ and/or hypoventilation to begin NIV. Clear benefits to this approach have been demonstrated in this study and that of Brasil Santos $e t a l^{7}$ for the Steroid Naïve group; however, the current study does not support this approach with the Steroid User group.

The mechanism by which LF decline is slowed in the Steroid Naïve group on NIV is likely to be similar to the beneficial effects of regular volume recruitment on peak $\mathrm{LF}$ and rates of decline in DMD. ${ }^{19-21}$ The proposed mechanism is provision of re-inflation of atelectatic areas of the lung, improved airway clearance, movement of the chest wall with a reduction in chest wall contractures and improved chest wall compliance. No patient in our cohort uses regular volume recruitment when well, so it is unlikely that the change in rate of decline in LF relates to infrequent and intermittent use of lung volume 
recruitment alone. This mechanism may also explain why adherence to NIV did not affect rates of decline in LF, as only short periods of NIV use provides lung inflation and chest wall movement.

This study spans a 10-year period, beginning before the recent Birnkrant et al's 2018 publication. ${ }^{11}$ Generally peak in $\mathrm{TcCO}_{2}>55 \mathrm{~mm} \mathrm{Hg}$ was used to indicate nocturnal hypoventilation. Since March 2018, the $2 \%$ TST $>50 \mathrm{~mm}$ $\mathrm{Hg}$ has been adopted. This information is not available for older studies. The last 12 (41.4\%) diagnostic PSG were evaluated by both criteria and no patient had hypoventilation classified incorrectly. It is unlikely that patients would have changed hypoventilation classification when the newer hypoventilation criteria are applied given the good correlation.

The similarities in diagnostic PSG parameters prior to starting NIV reflect the criteria used to start NIV. The higher $\mathrm{TcCO}_{2}$ peaks in the Steroid Naïve group may reflect more rapid progression of sleep hypoventilation between sleep studies, but this possibility has not been addressed by the current study and would require further investigation.

Subjects were seen at the same institution both before and following NIV initiation, and serial LF was available for both time periods. This offers a clear benefit in understanding the rates of decline before and after the intervention (NIV initiation) and differs to the previously available literature. ${ }^{7}$ The rates of decline pre-NIV and post-NIV initiation were higher than those reported by Brasil Santos et al (pre-NIV 8.15 vs $4.28 \%$ pa and post-NIV 4.16 vs $1.36 \%$ pa) for the Steroid Naïve group but they are similar to those reported by other groups. ${ }^{89}$

The main limitations of this study are its retrospective nature and its small patient numbers. All available subjects with DMD starting NIV at our institution were included. In a prospective study, possible confounders including patient weight, body habitus and scoliosis would have been included in further subgroup analysis, but this information was only sporadically available. There has been some conflict in the literature about the effect of spinal surgery on rates of decline in LF in DMD. ${ }^{22-24}$ However, it is likely, given the conflicting findings, that any effect on rate of decline in LF is small, and only one Steroid Naïve subject and no Steroid Users underwent spinal surgery. Likewise, the effects of body mass index and fat distribution have been examined for effect on FVC and sleep disordered breathing. ${ }^{25}{ }^{26}$ While both spinal deformity and body weight/habitus have the potential to add bias to the current study, the effects are likely to be small, and analysing their contribution would require large patient numbers.

It has been reported that FVC and left ventricular function decline in parallel and that right ventricular ejection fraction and right ventricular end diastolic volume is associated with FVC \% predicted; however, the present study did not find any association between LF decline and cardiac disease. ${ }^{27} 28$ The present study was longitudinal rather than cross-sectional and used only the presence of left ventricular ejection fraction $<50 \%$ or dilated cardiomyopathy to define significant cardiac disease, due to its retrospective nature. It may be that these measures are not sensitive enough to detect early cardiac disease.

\section{CONCLUSION}

This study has examined the effects of initiation of NIV in adolescent DMD boys where AHI $>5 /$ hour and/or nocturnal hypoventilation is present. It has found a beneficial effect of reducing the rate of decline in LF in Steroid Naïve subjects, but an unexpected acceleration in rate of decline of LF in the Steroid User group. While the study supports the early use of NIV in Steroid Naïve subjects, it necessitates further prospective research into the appropriate timing and long-term effects of NIV in the Steroid User group. This study does not support the current published criteria ${ }^{11}$ for early NIV use in long-term Steroid Users with DMD.

Contributors MEA contributed polysomnography and clinical data acquisition, drafting and revision. KDS contributed lung function data acquisition, drafting and revision of the work. LG contributed study design, analysis, interpretation, drafting and revision.

Funding The authors have not declared a specific grant for this research from any funding agency in the public, commercial or not-for-profit sectors.

Competing interests None declared.

Patient consent for publication Not required.

Ethics approval This study was reviewed by Children's Health Queensland Hospital and Health Service Human Research Ethics Committee and it was found to meet all requirements of sections 5.1.22 and 5.1.23 of the National Statement granting a waiver for formal ethics review.

Provenance and peer review Not commissioned; externally peer reviewed.

Data availability statement No data are available. Data used in the study are not publicly available.

Open access This is an open access article distributed in accordance with the Creative Commons Attribution Non Commercial (CC BY-NC 4.0) license, which permits others to distribute, remix, adapt, build upon this work non-commercially, and license their derivative works on different terms, provided the original work is properly cited, appropriate credit is given, any changes made indicated, and the use is non-commercial. See: http://creativecommons.org/licenses/by-nc/4.0/.

ORCID ID

Leanne Gauld http://orcid.org/0000-0003-0819-894X

\section{REFERENCES}

1 Passamano L, Taglia A, Palladino A, et al. Improvement of survival in Duchenne muscular dystrophy: retrospective analysis of 835 patients. Acta Myol 2012;31:121-5.

2 Villanova M, Brancalion B, Mehta AD. Duchenne muscular dystrophy: life prolongation by noninvasive ventilatory support. Am J Phys Med Rehabil 2014;93:595-9.

3 Vianello A, Bevilacqua M, Salvador V, et al. Long-Term nasal intermittent positive pressure ventilation in advanced Duchenne's muscular dystrophy. Chest 1994;105:445-8.

4 Shneerson JM, Simonds AK. Noninvasive ventilation for chest wall and neuromuscular disorders. Eur Respir J 2002;20:480-7.

5 Raphaël JC, Dazord A, Jaillard P, et al. [Assessment of quality of life for home ventilated patients with Duchenne muscular dystrophy]. Rev Neurol 2002;158:453-60.

6 Raphael P, Chevet S. Randomised trial of preventive nasal ventilation in Duchenne muscular dystrophy. The Lancet 1994;343:1600-4.

7 Brasil Santos D, Vaugier I, Boussaid G, et al. Impact of noninvasive ventilation on lung volumes and maximum respiratory pressures in Duchenne muscular dystrophy. Respir Care 2016;61:1530-5. 
8 Sawnani H, Horn PS, Wong B, et al. Comparison of pulmonary function decline in steroid-treated and Steroid-Naiive patients with Duchenne muscular dystrophy. J Pediatr 2019;210:194-200.

9 McDonald CM, Gordish-Dressman H, Henricson EK, et al. Longitudinal pulmonary function testing outcome measures in Duchenne muscular dystrophy: long-term natural history with and without glucocorticoids. Neuromuscular Disorders 2018;28:897-909.

10 Berry RB, Budhiraja R, Gottlieb DJ, et al. Rules for scoring respiratory events in sleep: update of the 2007 AASM manual for the scoring of sleep and associated events. deliberations of the sleep apnea definitions Task force of the American Academy of sleep medicine. J Clin Sleep Med 2012;8:597-619.

11 Birnkrant DJ, Bushby K, Bann CM, et al. Diagnosis and management of Duchenne muscular dystrophy, part 2: respiratory, cardiac, bone health, and orthopaedic management. Lancet Neurol 2018;17:347-61.

12 Gauld LM, Kappers J, Carlin JB, et al. Prediction of childhood pulmonary function using ulna length. Am J Respir Crit Care Med 2003:168:804-9.

13 Lofaso F, Quera-Salva MA. Polysomnography for the management of progressive neuromuscular disorders. Eur Respir J 2002;19:989-90.

14 Fauroux B, Lofaso F. Non-Invasive mechanical ventilation: when to start for what benefit? Thorax 2005;60:979-80.

15 Toussaint M, Chatwin M, Soudon P. Review article: mechanica ventilation in Duchenne patients with chronic respiratory insufficiency: clinical implications of 20 years published experience. Chron Respir Dis 2007;4:167-77.

16 Finder JD, Birnkrant D, Carl J, et al. Respiratory care of the patient with Duchenne muscular dystrophy: ATS consensus statement. Am J Respir Crit Care Med 2004;170:456-65.

17 Simonds AK, Muntoni F, Heather S, et al. Impact of nasal ventilation on survival in hypercapnic Duchenne muscular dystrophy. Thorax 1998;53:949-52.

18 Ward S, Chatwin M, Heather S. Randomised controlled trial of non-invasive ventilation (NIV) for nocturnal hypoventilation in neuromuscular and chest wall disease patients with daytime normocapnia. Thorax 2005;60:1019-24.

19 McKim DA, Katz SL, Barrowman N, et al. Lung volume recruitment slows pulmonary function decline in Duchenne muscular dystrophy. Arch Phys Med Rehabil 2012;93:1117-22.

20 Chiou M, Bach JR, Jethani L, et al. Active lung volume recruitment to preserve vital capacity in Duchenne muscular dystrophy. J Rehabil Med 2017;49:49-53.

21 Katz SL, Barrowman N, Monsour A, et al. Long-Term effects of lung volume recruitment on maximal inspiratory capacity and vital capacity in Duchenne muscular dystrophy. Ann Am Thorac Soc 2013:13:217-22.

22 Kennedy JD, Staples AJ, Brook PD, et al. Effect of spinal surgery on lung function in Duchenne muscular dystrophy. Thorax 1995;50:1173-8.

23 Alexander WM, Smith M, Freeman BJC, et al. The effect of posterior spinal fusion on respiratory function in Duchenne muscular dystrophy. Eur Spine J 2013;22:411-6.

24 Velasco MV, Colin AA, Zurakowski D, et al. Posterior spinal fusion for scoliosis in Duchenne muscular dystrophy diminishes the rate of respiratory decline. Spine 2007;32:459-65.

25 Chew K, Carey K, Ho G, et al. The relationship of body habitus and respiratory function in Duchenne muscular dystrophy. Respir Med 2016;119:35-40.

26 Canapari CA, Barrowman N, Hoey L, et al. Truncal fat distribution correlates with decreased vital capacity in Duchenne muscular dystrophy. Pediatr Pulmonol 2015;50:63-70.

27 Khokhar A, Nair A, Midya V, et al. Association between pulmonary function and left ventricular volume and function in Duchenne muscular dystrophy. Muscle Nerve 2019;60:286-91.

28 Mehmood M, Ambach SA, Taylor MD, et al. Relationship of right ventricular size and function with respiratory status in Duchenne muscular dystrophy. Pediatr Cardiol 2016;37:878-83. 